(2) Open Access Full Text Article

\title{
Potential utility of precision medicine for older adults with polypharmacy: a case series study
}

This article was published in the following Dove Press journal:

Pharmacogenomics and Personalized Medicine

15 April 2016

Number of times this article has been viewed

\author{
Joseph Finkelstein' \\ Carol Friedman' \\ George Hripcsak' \\ Manuel Cabrera ${ }^{2}$ \\ 'Department of Biomedical \\ Informatics, ${ }^{2}$ Department of Medicine, \\ Columbia University, New York, NY, \\ USA
}

Correspondence: Joseph Finkelstein 622 West 168th Street, $\mathrm{PH}-20$,

Room 40IA, New York, NY 10032, USA

Tel +l 9174773909

Email jf193@cumc.columbia.edu
Abstract: Pharmacogenomic (PGx) testing has been increasingly used to optimize drug regimens; however, its potential in older adults with polypharmacy has not been systematically studied. In this hypothesis-generating study, we employed a case series design to explore potential utility of PGx testing in older adults with polypharmacy and to highlight barriers in implementing this methodology in routine clinical practice. Three patients with concurrent chronic heart and lung disease aged 74, 78, and 83 years and whose medication regimen comprised 26, 17, and 18 drugs, correspondingly, served as cases for this study. PGx testing identified major genetic polymorphisms in the first two cases. The first case was identified as "CYP3A4/ CYP3A5 poor metabolizer", which affected metabolism of eleven prescribed drugs. The second case had "CYP2D6 rapid metabolizer" status affecting three prescribed medications, two of which were key drugs for managing this patient's chronic conditions. Both these patients also had VKORC1 allele *A, resulting in higher sensitivity to warfarin. All cases demonstrated a significant number of potential drug-drug interactions. Both patients with significant drug-gene interactions had a history of frequent hospitalizations (six and 23, respectively), whereas the person without impaired cytochrome P450 enzyme activity had only two acute episodes in the last 5 years, although he was older and had multiple comorbidities. Since all patients received guideline-concordant therapy from the same providers and were adherent to their drug regimen, we hypothesized that genetic polymorphism may represent an additional risk factor for higher hospitalization rates in older adults with polypharmacy. However, evidence to support or reject this hypothesis is yet to be established. Studies evaluating clinical impact of PGx testing in older adults with polypharmacy are warranted. For practical implementation of pharmacogenomics in routine clinical care, besides providing convincing evidence of its clinical effectiveness, multiple barriers must be addressed. Introduction of intelligent clinical decision support in electronic medical record systems is required to address complexities of simultaneous druggene and drug-drug interactions in older adults with polypharmacy. Physician training, clear clinical pathways, evidence-based guidelines, and patient education materials are necessary for unlocking full potential of pharmacogenomics into routine clinical care of older adults.

Keywords: precision medicine, pharmacogenomics, polypharmacy, elderly, case series

\section{Background}

Multiple epidemiological studies clearly demonstrated that polypharmacy is highly prevalent in older adults. ${ }^{1}$ Based on the 2005-2006 survey study, $>36 \%$ of people between 75 and 85 years of age were taking at least five prescription medications. ${ }^{2}$ A strong relationship between polypharmacy and negative clinical consequences has been described in previous research. ${ }^{3}$ In older adults, polypharmacy has been associated 
with increased health care costs, adverse drug reactions (ADRs), drug interactions, medication nonadherence, impaired functional and cognitive status, falls, urinary incontinence, and malnutrition. ${ }^{3}$ Not surprisingly, polypharmacy and potentially inappropriate medication use were shown to be significant precipitating factors in frequent hospital admissions. $^{4}$

Precision medicine can provide tools enabling personalized medication regimens based on individual genetic variations and information about potential drug interactions obtained from comprehensive bioinformatic repositories. Pharmacogenomics is the study of how persons' unique genetic makeup influences their response to drugs. It is one of the cornerstones of personalized medicine in which the use of drugs and drug combinations can be expected to be tailored to patient's unique genetic profile. The availability of genomic testing has grown, but its clinical application is still in the early stages. The US Food and Drug Administration (FDA) now requires submission of pharmacogenomic (PGx) data to be included in the labeling of drugs. ${ }^{5}$ Genetic biomarker testing is mentioned in labels of 140 FDA-approved drugs corresponding to 158 drug biomarker pairs, and the number of such drugs is rapidly increasing. ${ }^{6}$ This has the expectation that PGx information may improve drug safety, identify optimal dosing, improve targeting to disease, and reduce ADRs.

Particular attention in pharmacogenomics has been devoted to cytochrome P450 (CYP) enzymes, which are involved in the metabolism of $70 \%-90 \%$ of all prescribed drugs. The most common CYP enzymes involved in drug metabolism are CYP2D6, CYP2C9, CYP2C19, CYP3A4, and CYP3A5. ${ }^{7}$ With these enzymes, there may be many spectrums of genotypes resulting in poor metabolizers (patients with little to no functional enzyme activity) to ultrarapid metabolizers (patients with increased enzyme activity). ${ }^{8}$ In a recent review, positive PGx findings were identified for $72 \%$ of cardiovascular drugs suggesting that considerable clinically actionable PGx information exist for majority of cardiovascular drugs. ${ }^{9}$ This knowledge is already being applied clinically to the use of warfarin and clopidogrel with growing number of cardiologists having reported using genomic testing. ${ }^{9}$ For example, the cytochrome enzyme CYP2C9 along with VKORC1 is the primary enzyme affecting efficacy of warfarin. ${ }^{10}$ Known allele variants $(\mathrm{CYP} 2 \mathrm{C} 9 * 2 / * 2$, CYP2C9*2/*3, and CYP2C $9 * 3 / * 3$ ) have been shown to result in $60 \%-80 \%$ decrease in enzyme activity in patients with the variant, and therefore, those patients would likely be very sensitive to the anticoagulant effect of warfarin, indicating a need for use of lower dosing. ${ }^{10}$ Clopidogrel is activated via CYP2C19, and allele variants affecting its function are also well described..$^{10}$ The prevalence of allele variants greatly depends on race and ethnicity. ${ }^{11,12}$ For example, prevalence of CYP poor metabolizer genotype for 2D6, 2C9, and 2C19 in Caucasians was reported to be $10 \%, 5 \%$, and $3 \%$, correspondingly. ${ }^{13,14}$ All known PGx variants are readily available on the PharmGKB website. ${ }^{15,16}$

Comorbidities are common in older adults, which result in high prevalence of polypharmacy in this population. ${ }^{17}$ Altered metabolism and the presence of geriatric syndromes make older adults with polypharmacy more likely to experience adverse drug events and hospitalization. Previous studies demonstrated that hospitalization rates may vary widely in older adults even with similar levels of disease severity. For example, the median number of hospital admissions in older persons newly diagnosed with heart failure was reported to be three, with $\sim 30 \%$ having less than two admissions and $\sim 25 \%$ having more than five admissions annually. ${ }^{18}$ Given that patients with similar comorbidities and disease severity are receiving guideline-concordant care and are adherent to their treatment regimen, the potential source of wide disparity in hospitalization rates may be different efficacies of drug therapy due to differences in individual response to certain medications. Targeted genomic testing can help identify older adults whose drug metabolism or pharmacodynamics is affected by genetic makeup and subsequently lead to better personalization of drug therapy.

However, for physicians and health care professionals in practice, the clinical utility and integration in patient care of pharmacogenomics remain uncertain and mostly unexplored. There are many issues regarding genetic testing from simple ones on how and where can testing be done to more complex issues as to which patients to test, how to interpret the results of testing, and then how to apply the findings to decision making that may benefit the patient. ${ }^{19}$ Limited information exists on the utility of PGx testing in older adults with polypharmacy. The important question to investigate is whether genetic testing data can be effectively used in clinical practice for older adults with polypharmacy to tailor drug treatments, reduce adverse drug effects, reduce polypharmacy, and eventually improve disease outcome.

Whether precision medicine can provide effective means to ameliorate the detrimental impact of polypharmacy in older adults is currently unknown. The goal of this article is to share our experience in PGx testing of three older adults with polypharmacy. By reviewing these cases, we intend to explore potential benefits and possible barriers of precision 
medicine application in older adults with polypharmacy in this hypothesis-generating study.

\section{Methods}

A case series study design was employed. Three patients seen in outpatient clinical practice served as cases in this study. These patients had both chronic heart and lung disease and were on numerous medications. They expressed concern about having to take so many medications and requested evaluation of their medical regimen. The three patients were receiving guideline-concordant therapy under the care of a pulmonologist and a cardiologist and were reported to be compliant with medical care. The patients were offered to undergo PGx testing by a treating physician in order to optimize their therapy.

Initially, a certified testing facility licensed in the State of New York had to be identified. After several rounds of inquiries, a New York State-licensed personalized medicine laboratory (GENETWORx, LLC) was identified, which was accredited by College of American Pathologists Laboratory Accreditation Program and had Clinical Laboratory Improvement Act certification. Among other tests, the laboratory carries out PGx testing to detect common variants in genes that may affect individual response to medications. The GENETWORx Comprehensive PGRx Panel detects all common and many rare genetic variants with known clinical significance.

The genetic variants tested in this study are listed in Figure 1. Laboratory specimens were analyzed for the target genes using the GENETWORx Personalized Medicine Panel. The assay is based on the bead-based multiplex xTAG chemistry from Luminex Corporation. The CYP2D6 assay is an in vitro diagnostic assay from Luminex Corporation that also uses their xTag Technology. Genomic DNA is extracted from the submitted specimen and amplified by the polymerase chain reaction (PCR) using consensus oligonucleotide primers specific for the variants listed earlier. Genomic DNA is amplified in a multiplex fashion. The PCR is then subjected to a primer extension step that is specific for the allele that is being analyzed: allele-specific primer extension. The $5^{\prime}$ end of the primers for allele-specific primer extension is attached to an XTAG universal tag sequence. The $5^{\prime}$ universal tag sequence is hybridized to the complementary anti-tag sequence coupled to a particular XMAP bead set that is then detected by the XMAP Luminex 200 analyzer.

The CYP2C19PLUS and CYP2D6 assays from AutoGenomics detect the wild type and polymorphic alleles of the CYP2C19 and CYP2D6 genes, respectively. Genomic DNA was extracted from the submitted specimen and amplified by the PCR using consensus oligonucleotide primers specific for the desired analyte. A fluorescent labeling primer extension reaction was performed in the presence of Cy5 $\mathrm{dCTP}$ using primers containing nontarget nucleotide sequences that were complimentary to the capture oligonucleotides spotted on the microarray. Labeled samples were hybridized onto microarrays, and the fluorescent signal was measured, analyzed, and reported.

The laboratory provided testing kits including instructional materials, consent forms, and buccal swab tools. After a patient signed consent for genetic testing approved by Columbia University Institutional Review Board, a buccal swab was collected from inside each cheek, placed in the provided envelopes, and returned to the laboratory via an overnight express mail. The results of the testing were provided by the testing facility via a password-protected secure online portal a week after submission of the buccal swabs. The portal contained a detailed report with results of the genetic testing as well as interpretation of findings. The portal also provided basic education materials explaining the general principles of PGx testing.

\section{Results}

All patients successfully underwent PGx testing. It took $<10$ minutes to collect buccal swabs from each patient. The testing results became available online in five working days after the swab submission. A clinical summary of the case series is provided in Table 1.

\section{Case \#I}

The Case \#1 is a 74-year-old Dominican woman with a history of hypertension, diabetes, hyperlipidemia, diastolic

- CYP2C19: *1 (WT/Normal), *2 (19154G>A), *3 (17948G>A), *4 (1A>G), *5 (90033C > T), *6 (12748G>A), *7 (19294T>A), *8 (12711T>C), *9 $(12784 \mathrm{G}>\mathrm{A}),{ }^{*} 10(19153 \mathrm{C}>\mathrm{T}),{ }^{*} 17(-806 \mathrm{C}>\mathrm{T})$

- CYP2C9: *1 (WT/Normal)*2 $(430 \mathrm{C}>\mathrm{T}), \mathrm{VKORC1}(-3673 \mathrm{G}>\mathrm{A})$

- CYP2D6: *1 (WT/Normal), ${ }^{*} 2(2850 \mathrm{C}>\mathrm{T}),{ }^{*} 3(2549 \mathrm{delA}),{ }^{*} 4(1846 \mathrm{G}>\mathrm{A}),{ }^{*} 5$ (deletion), ${ }^{*} 6(1707 \mathrm{del}),{ }^{*} 7(2935 \mathrm{~A}>\mathrm{C}),{ }^{*} 8(1785 \mathrm{G}>\mathrm{T}),{ }^{*} 9$ $\left(2615 \_2617\right.$ delAAG), ${ }^{*} 10(100 \mathrm{C}>\mathrm{T}),{ }^{*} 12(124 \mathrm{G}>\mathrm{A}),{ }^{*} 14(1785 \mathrm{G}>\mathrm{A}),{ }^{*} 17(1023 \mathrm{C}>\mathrm{T}),{ }^{*} 29(1659 \mathrm{G}>\mathrm{A}),{ }^{*} 41(2988 \mathrm{G}>\mathrm{A}),{ }^{*} \mathrm{XN}$ (Duplication)

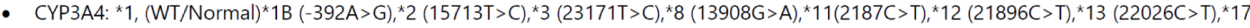
$(15615 T>C) * 22(15389 C>T)$

- CYP3A5: *1 (WT/Normal), *2 (27289C>A), *3 (6986A>G), *3B (3709_3710insG), *6 (14690G>A), *7 (27131_27132insT), *8(3699C>T) *9 $(19386 \mathrm{G}>\mathrm{A})$

Figure I Genetic variants tested in the study. 
Table I Clinical summary of case series

\begin{tabular}{|c|c|c|}
\hline Case \#I & Case \#2 & Case \#3 \\
\hline \multicolumn{3}{|l|}{ Demographics } \\
\hline 74-Year-old/female/Hispanic/White & 78-Year-old/male/Hispanic/White & 83-Year-old/male/non-Hispanic/White \\
\hline \multicolumn{3}{|l|}{ Comorbidities } \\
\hline $\begin{array}{l}\text { Asthma, COPD, CHF, hypertension, } \\
\text { type } 2 \text { diabetes, hyperlipidemia }\end{array}$ & $\begin{array}{l}\mathrm{CHF} \text {, atrial fibrillation, CKD, COPD, } \\
\text { hyperlipidemia, gout, } \mathrm{BPH}, \mathrm{GERD} \text {, } \\
\text { Patent Foramen Ovale, gastritis }\end{array}$ & $\begin{array}{l}\text { COPD, atrial flutter, hypertension, } \\
\text { herpes zoster, polyneuropathy }\end{array}$ \\
\hline \multicolumn{3}{|l|}{ Medications } \\
\hline Albuterol sulfate & Albuterol sulfate & Albuterol sulfate \\
\hline Aspirin & Allopurinol & Amiodarone $\mathrm{HCl}$ \\
\hline Atorvastatin calcium & Atorvastatin calcium & Aspirin \\
\hline Clonidine $\mathrm{HCl}$ & Calcitriol & Dabigatran etexilate mesylate \\
\hline Diclofenac potassium & Carvedilol & Digoxin \\
\hline Esomeprazole magnesium & Diltiazem $\mathrm{HCl}$ & Diltiazem $\mathrm{HCl}$ \\
\hline Fluticasone propionate & Esomeprazole magnesium & Dimethyl sulfoxide \\
\hline Fluticasone/salmeterol & Ferrous sulfate & Esomeprazole magnesium \\
\hline Furosemide & Fluocinonide & Fluticasone/vilanterol \\
\hline Lidocaine/prilocaine & Fluticasone/vilanterol & Furosemide \\
\hline Losartan/hydrochlorothiazide & Furosemide & Gabapentin \\
\hline Meclizine $\mathrm{HCl}$ & Losartan potassium & Lidocaine \\
\hline Memantine $\mathrm{HCl}$ & Montelukast sodium & Losartan potassium \\
\hline Metoclopramide $\mathrm{HCl}$ & Naproxen & Montelukast \\
\hline Metolazone & Olopatadine hydrochloride & Polyethylene glycol 3350 \\
\hline Metoprolol succinate & Tamsulosin $\mathrm{HCl}$ & Pregabalin \\
\hline Montelukast sodium & Warfarin sodium & Tamsulosin $\mathrm{HCl}$ \\
\hline Nitrofurantoin monohyd/M-cryst & & Tiotropium bromide \\
\hline \multicolumn{3}{|l|}{ Nortriptyline $\mathrm{HCl}$} \\
\hline \multicolumn{3}{|l|}{ Olopatadine $\mathrm{HCl}$} \\
\hline \multicolumn{3}{|l|}{ Oxybutynin chloride } \\
\hline \multicolumn{3}{|l|}{ Prednisone } \\
\hline \multicolumn{3}{|l|}{ Primidone } \\
\hline \multicolumn{3}{|l|}{ Roflumilast } \\
\hline \multicolumn{3}{|l|}{ Sitagliptin phos/metformin $\mathrm{HCl}$} \\
\hline \multicolumn{3}{|l|}{ Tiotropium bromide } \\
\hline \multicolumn{3}{|l|}{ Hospitalization history } \\
\hline Six hospitalizations in the past 5 years & 23 hospitalizations in the past 5 years & Two hospitalizations in the past 5 years \\
\hline
\end{tabular}

Abbreviations: $\mathrm{CHF}$, congestive heart failure; CKD, chronic kidney disease; BPH, benign prostatic hyperplasia; GERD, gastroesophageal reflux disease; COPD, Chronic Obstructive Pulmonary Disease.

heart failure, and asthma for 30 years. She has had six hospitalizations within the past 5 years, all for shortness of breath. The hospitalizations were often due to bronchospasm. Several hospitalizations were accompanied by peripheral edema associated with elevated N-terminal pro b-type natriuretic peptide level where the medical team felt that her decompensation was due to exacerbation of both her airways disease and diastolic heart failure. During all of her hospitalizations, she was treated with systemic corticosteroids and nebulized bronchodilators and sometimes given Lasix for "respiratory distress" or edema. She was usually discharged on prednisone $60 \mathrm{mg}$ with taper as well as Lasix. Left ventricular ejection fraction was between $65 \%$ and $70 \%$.

PGx testing in the Case \#1 identified two singlenucleotide polymorphisms (Table 2). The polymorphism of major importance was found in the CYP3A5 gene for which mutant alleles $* 3 / * 6$ were identified. ${ }^{20}$ These alleles result in expression of nonfunctional isoform and lead to the CYP3A4/ CYP3A5 poor metabolizer status. ${ }^{21}$ Another polymorphism was found in the VKORC1 gene. ${ }^{22}$ The VKORC1 genetic variant $* \mathrm{~A} /{ }^{*} \mathrm{~A}$ results in an isoform, which has low enzyme activity leading to higher sensitivity to warfarin. ${ }^{23}$

Figure 2 summarizes potential drug-gene and drugdrug interactions based on CYP450 metabolism found in the Case \#1. Drug-gene interactions in this patient involved multiple medications. They comprised CYP3A4/CYP3A5 substrates (atorvastatin, fluticasone/salmeterol, lidocaine, losartan, montelukast, prednisone, and roflumilast) that are metabolized by CYP3A4/CYP3A5. In addition to multiple drug-gene interactions, numerous potential drug-drug interactions (PDDIs) were identified. They included five PDDIs based on CYP450 metabolism and eleven non-CYP450 
Table 2 Genotype/phenotype results

\begin{tabular}{|c|c|c|c|}
\hline Gene panel & Case \#I & Case \#2 & Case \#3 \\
\hline \multirow[t]{2}{*}{ CYP2CI9 } & $* 1 / * 1$ & $* \mid / * 1$ & $* 1 / * 1$ \\
\hline & Normal metabolizer & Normal metabolizer & Normal metabolizer \\
\hline \multirow[t]{2}{*}{ CYP2C9/VKORCI } & $* 1 / * 1 / * \mathrm{~A} / * \mathrm{~A}$ & $* \mathrm{I} / * \mathrm{I} / * \mathrm{G} / * \mathrm{~A}$ & $* \mathrm{I} / * \mathrm{I} / * \mathrm{G} / * \mathrm{G}$ \\
\hline & Normal metabolizer/high sensitivity & Normal metabolizer/intermediate sensitivity & Normal metabolizer/low sensitivity \\
\hline \multirow[t]{2}{*}{ CYP2D6 } & $* 2 / * 4$ & $* \mathrm{I} / * 2(\mathrm{XN})$ & $* 1 / * 4$ \\
\hline & Normal metabolizer & Rapid metabolizer & Normal metabolizer \\
\hline \multirow[t]{2}{*}{ CYP3A4/CYP3A5 } & $*|/| B / * 3 / * 6$ & $* 1 / * 1 / * 3 / * 3$ & $* 1 / * 1 / * 3 / * 3$ \\
\hline & Poor metabolizer & Normal metabolizer & Normal metabolizer \\
\hline
\end{tabular}

Note: Bold entries indicate significant cytochrome polymorphism.

PDDIs of various clinical importance. A detailed list of all interactions with explanation of interaction mechanism and its clinical impact can be found in Table S1.

\section{Case \#2}

The Case \#2 is a 78-year-old Puerto Rican man with a history of multiple medical problems prominent of which is congestive heart failure (CHF) and chronic obstructive pulmonary disease (COPD). The patient has had 23 hospitalizations over the past 5 years where most of his hospitalizations were due to decompensated heart failure. Several of the hospitalizations were for COPD exacerbations with wheezing as the presenting symptom. Many hospitalizations were deemed by his medical team to be due to exacerbation of both heart and lung disease. The patient had systolic heart failure where the left ventricle size was mildly increased. The left ventricular systolic function was moderately to severely decreased with a left ventricular ejection fraction of $30 \%-35 \%$. There was global hypokinesis with regional variations. The right ventricular size was mildly increased with right ventricular systolic function preserved. The patient also suffered from COPD with forced expiratory volume in the first second of $52 \%$ predicted. He was an $\sim 50$ pack/year smoker. In addition, he suffered from atrial fibrillation, chronic kidney disease (estimated glomerular filtration rate of $23 \mathrm{~mL} / \mathrm{min}$ ), hyperlipidemia, gout, benign prostatic hyperplasia, and gastritis.
Results of PGx testing of Case \#2 identified two mutations related to the genes CYP2D6 and VKORC1. In the Case \#2, multiple copies of the CYP2D6 gene were expressed resulting in CYPD26 rapid metabolizer status and therefore greater-than-normal CYP2D6 function. ${ }^{24}$ The CYP2D6 rapid metabolizer status resulted in drug-gene interaction in this patient affecting carvedilol, diltiazem, and tamsulosin which are metabolized by CYP2D6. ${ }^{25}$ This interaction may potentially lead to decreased bioavailability of carvedilol taken in standard doses. ${ }^{26}$ The VKORC1 mutation was represented in this patient by gene polymorphism of type * $\mathrm{G} /{ }^{*} \mathrm{~A}$, which results in reduced VKORC1 enzyme activity. ${ }^{23}$

Figure 3 provides a summary of potential drug-gene and drug-drug interactions related to CYP450 metabolism that were identified in the Case \#2. A major drug-gene interaction in this patient involved carvedilol, which is a substrate for CYP2D6 enzyme. As in the Case \#1, in addition to multiple drug-gene interactions, numerous PDDIs were identified. They included three PDDIs based on CYP450 metabolism and seven non-CYP450 PDDIs of various clinical importance. Table S2 provides a detailed overview of all interactions with explanation of interaction mechanism and its clinical impact.

\section{Case \#3}

The Case \#3 is an 83-year-old man of Italian and Greek descent with a history of COPD, hypertension, and obesity.

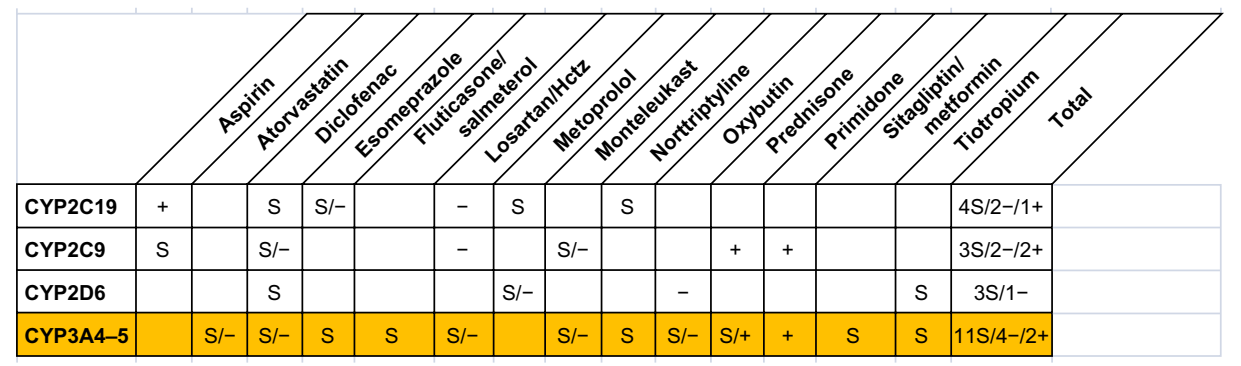

Figure 2 Potential drug-gene and drug-drug interactions in the Case \#I.

Notes: S: substrate; +: inducer; -: inhibitor; yellow background: mutant allele.

Abbreviation: Hctz, hydrochlorothiazide. 


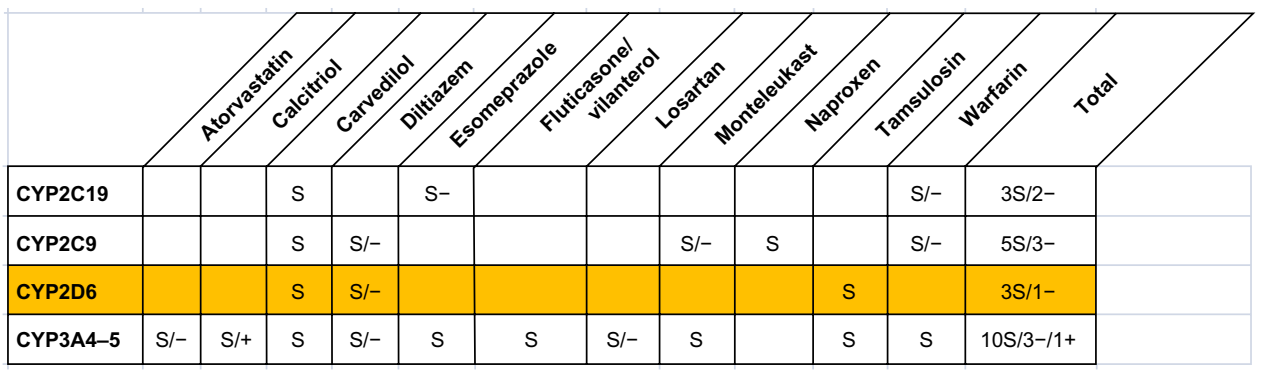

Figure 3 Potential drug-gene and drug-drug interactions in the Case \#2.

Notes: S: substrate; +: inducer; -: inhibitor; yellow background: mutant allele.

He continues to smoke cigars. The patient has two hospitalizations within the past 5 years, and three known COPD exacerbations managed as outpatient. His course has been complicated by atrial flutter after ablation therapy and requiring complex medical management.

Unlike drug-gene interactions identified in Cases \#1 and \#2, no genetic mutations related to CYP450 drug metabolism were found in the Case \#3. Three PDDIs related to CYP450 and five non-CYP450 potential interactions were noted. A summary of potential CYP450-based interactions is presented in Figure 4. A detailed list of all PDDIs in the Case \#3 can be found in Table S3.

\section{Discussion}

Genotype testing was performed in older adults with a large number of prescribed medications in an attempt to reevaluate their medical management. The results of three cases of PGx testing in older adults with polypharmacy have been reviewed in this article using case series design. The purpose of this case review was hypothesis-generating exploration of potential utility of precision medicine applications in older adults with polypharmacy as well as better understanding of challenges in implementing this promising methodology in routine clinical care.

The major finding in the results of PGx testing of Case \#1 was single-nucleotide polymorphism of CYP3A5 gene. The
CYP3A family is a well-described Phase I metabolismrelated gene family, which includes CYP3A4 and CYP3A5 genes located in the $231 \mathrm{~kb}$ region of chromosome 7q21.1.20,21 CYP3A4 and CYP3A5 are closely related and metabolize many of the same drugs. CYP3A4/CYP3A5 comprises $\sim 30 \%$ of the total cytochrome enzymes in the liver. Genetic variations in CYP3A4 and CYP3A5 may result in dramatic differences in enzyme activity between individuals. ${ }^{20}$

The combination of CYP3A5 alleles $* 3 / * 6$ identified in the Case \#1 results in significant reduction of CYP3A5 enzymatic activity. ${ }^{20}$ Only $7.2 \%$ of subjects were identified as CYP3A5 poor metabolizers in a mixed-race population of $>20,000$ US patients. ${ }^{27}$ Ethnic frequency of allelic variant CYP3A5*6 was reported for Caucasians, AfricanAmericans, Asians, Hispanics, and Africans to be $0.43 \%$, $11.9 \%, 0 \%, 3.7 \%$, and $16.8 \%$, respectively. ${ }^{12}$ For the Case \#1, the atorvastatin, diclofenac, esomeprazole, fluticasone/ salmeterol, losartan/hydrochlorothiazide, montelukast, nortriptyline, oxybutynin, prednisone, sitagliptin/metformin, and tiotropium are substrates of CYP3A4/CYP3A5 enzymes, the activity of which may be impaired due to the presence of mutant alleles. Because she is a "poor metabolizer", the substrate drugs of the CYP3A4/CYP3A5 may be expected to accumulate and increase the risk of adverse drug effects. For this patient, management considerations may include changing the atorvastatin to rosuvastatin, which does not utilize the

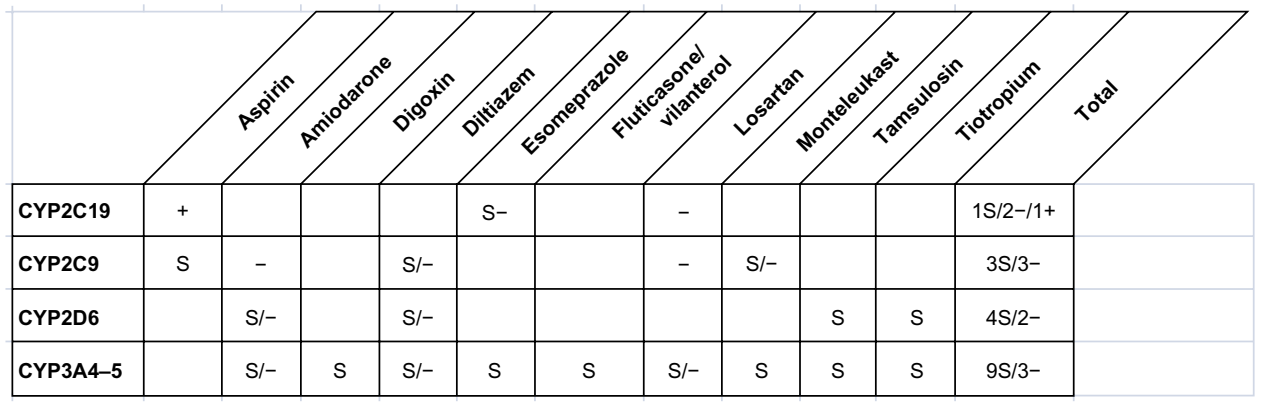

Figure 4 Potential drug-gene and drug-drug interactions in the Case \#3. Notes: S: substrate; +: inducer; --: inhibitor. 
CYP3A4/CYP3A5 pathway, and eliminating salmeterol and monteleukast and others. However, a decision to change or eliminate potentially inappropriate medications in this patient is complicated by the complex interaction of polypharmacy and lack of clear evidence-based guidelines for optimal drug changes under such circumstances. Figure 2 shows eleven substrates including four inhibitors and two inducers for CYP3A4/CYP3A5 found to be affected by mutant alleles in the Case \#1. Most studies to date have looked at one drug with one gene polymorphism as with warfarin and clopidogrel; however, PGx studies need to look at patient on multiple drugs.

Another polymorphism found in the Case \#1 affected VKORC1 which codes for vitamin $\mathrm{K}$ epoxide reductase (VKOR) that is the target of warfarin therapeutic action. Warfarin acts in the vitamin $\mathrm{K}$ cycle by interfering with the regeneration of reduced vitamin $\mathrm{K}$ in VKOR complex. Mutations in the VKORC1 gene cause decreased VKORC1 enzyme activity. The VKORC1 allele *A in the Case \#1 has been shown to result in decreased VKOR enzyme activity making patient more sensitive to warfarin. ${ }^{22,23} \mathrm{~A}$ recent assessment of PGx marker panel in a polypharmacy population identified $13 \%$ of subjects with VKORC1 AA genotype. ${ }^{14}$

As presented in Table S1, in addition to drug-gene interactions, multiple PDDIs due to cytochrome metabolism and nonCYP interactions were identified in the Case \#1. Coexistence of both heart and airways disease is known to sometimes create therapeutic dilemmas, such as weighing the benefits of betablockers versus the fear of exacerbating coexistent airways obstruction, as well as weighing the potential increase in risk of death with the use of long acting beta-agonists. This dilemma may be further complicated when drug regimen includes medications which are metabolized by enzymes that are inhibited or induced by other medications taken simultaneously.

Table S1 lists seven drug-gene interactions, five CYP450based PDDIs, and eleven non-CYP450 drug-drug interactions found in the Case \#1. This case illustrates that in people with polypharmacy and CYP450 polymorphisms comprehensive approaches for medication regimen optimization are needed allowing simultaneously account for various types of multiple drug and gene interactions. It is also worth noting in this patient that prednisone, which is the primary treatment of her asthma exacerbations, requires the CYP3A4/CYP3A5 enzymes for conversion to its active form. This should raise concerns regarding the efficacy of prednisone in the management of acute exacerbations in this patient, since bioavailability of active form of prednisone (prednisolone) will be reduced under standard prescription dosage.
The Case \#2 was notable for identifying a CYP2D6 rapid metabolizer status. CYP2D6 metabolizes $\sim 25 \%$ of current drugs, and it is known for its large interindividual variation in the enzyme activity. ${ }^{24}$ Typical substrates for CYP2D6 are largely lipophilic bases and include some antidepressants, antipsychotics, antiarrhythmics, antiemetics, beta-adrenoceptor antagonists (beta-blockers), and opioids. ${ }^{28}$ Prevalence of CYP2D6 rapid metabolizers was reported to be $3 \%-5 \%$ in Caucasians. ${ }^{24}$ In a recent retrospective analysis of 1,143 individuals, frequency of allele duplications for CYP2D6 was found to be $1.8 \% .^{29}$ CYP2D6 rapid metabolizers are individuals with more than two alleles of an active CYP2D6 enzyme gene, which results in higher elimination of active CYP2D6 substrates. These individuals may need a higher than usual dose of medications to achieve a therapeutic effect.

In the Case \#2, carvedilol and diltiazem are considered key medications in management of his heart failure and atrial fibrillation. As is illustrated in Figure 3, these two drugs are metabolized by CYP2D6. Carvedilol is mainly metabolized in the liver through oxidation and glucuronidation. During this process, the oxidative enzyme CYP2D6 is considered a key component of carvedilol elimination. As a consequence of CYP2D6 rapid metabolizer phenotype, bioavailability of carvedilol can be maintained at therapeutically ineffective levels with a standard dosage prescription. ${ }^{24}$

A recent study demonstrated that the response to betablockers in patients with CHF was associated with genotype of drug-metabolizing enzymes. ${ }^{30}$ CYP2D6 genotype was significantly associated with the dose of carvedilol in patients with CHF whose dosage was titrated to a clinical response. ${ }^{30}$ Another study, which analyzed the plasma concentrations of carvedilol in four groups including extensive metabolizers (CYP2D6*1/*1), intermediate metabolizers (CYP2D6*1/*5 and $* 1 / * 10$ ), poor metabolizers (CYP2D6*5/*5 and *5/*10), and rapid metabolizers (CYP2D6*2xN/*10), found that the concentration was dependent on CYP2D6 genotypes. ${ }^{31}$ A recent review on the impact of CYP2D6 genetic variation on the response of cardiovascular patients to carvedilol concluded that mutant CYP2D6 alleles can result in elevated risks for either treatment failure or for adverse effects. ${ }^{25}$ Another report in a relatively small sample did not find an association between variations in the CYP2D6 genotype and carvedilol dose changes in patients with $\mathrm{CHF}^{32}$ however. Thus, though a majority of publications confirm significant effects of CYP2D6 polymorphism on carvedilol performance in patients with $\mathrm{CHF}$, there is no consensus on the extent of its effect, and on optimal actions to be undertaken to optimize therapy when a particular polymorphism is detected. 
In the Case \#2, rapid metabolism of the carvedilol and diltiazem may be expected to reduce their efficacy, but there is no consensus on clinical significance and appropriate course of actions in this case. Currently, widely accepted clinical guidelines for medication prescriptions in older adults with CYP polymorphisms do not exist. Studies on polymorphisms of beta1 and beta2 receptors have been inconclusive. Beta-blockers have a wide therapeutic index, and therefore, effectiveness and assessment of clinical outcomes would be difficult to determine. Additional evidence is necessary in order to establish if a "rapid metabolizing" polymorphism would reduce the known survival benefits of beta-blockers in CHF. The FDA has listed carvedilol among the drugs whose labels mention PGx information. However, mention of PGx biomarker in the drug label may lack definite actionable guidance. The Clinical Pharmacogenetics Implementation Consortium was formed to disseminate freely available, peerreviewed, updatable, and detailed gene/drug clinical practice guidelines that enable the translation of genetic laboratory test results into actionable prescribing decisions. ${ }^{33}$ In addition, the Royal Dutch Association for the Advancement of Pharmacy established the Pharmacogenetics Working Group with the objective of developing pharmacogenomics-based dose recommendations based on systematic review of the literature. ${ }^{34}$

Figure 3 illustrates the complexity of decision making in optimizing the medication regimen for the Case \#2. Even in the absence of mutant alleles of metabolizing cytochrome enzymes, there are multiple PDDIs based on cytochrome metabolism. The Case \#2 has ten drug substrates for the CYP3A4/5 enzyme, three of which are inhibitors of the enzyme and one of which is an inducer. When prescribing in an electronic medical record, physicians are often provided drug alerts. However, available alerts on drug interactions currently do not reflect the extent or complexity of PDDIs for typical older adults on polypharmacy as illustrated in Figure 3. An additional level of complexity is added when considering potential non-CYP drug-drug interactions listed in Table S2.

Current decision support for drug alerts lacks intelligent algorithms to deal with multiple drug-drug interactions along with drug-gene interactions, and is incapable of providing informed alternatives on optimal drug replacements in these complex cases. In the case of genetic polymorphisms, such as CYP2D6 rapid metabolizer status, decision support for drug-gene interactions is still in early development stages and has yet to be fully implemented. It is worth noting that it is well recognized and it is now a black box FDA warning that use of codeine in patients with CYP2D6 rapid metabolizing polymorphisms can lead to adverse consequences. Codeine is metabolized by CYP2D6 to the active form of morphine and other metabolites and rapid metabolizing polymorphisms can result in toxic concentration of morphine. Though codeine is not currently prescribed for the Case \#2, it might inadvertently be considered in the future. Thus, information on genetic polymorphism should be readily available in the electronic medical record and should support genetic information representation that is standardized and easily actionable by intelligent decision support in case a suboptimal prescription is made.

In the Case \#3, genotype testing showed wild allele phenotypes for the cytochrome enzymes tested. No genetic mutations were identified. Multiple PDDIs resulting from cytochrome metabolism and non-CYP interactions as shown in Table S3, again illustrate the complex interactions of polypharmacy and the cytochrome enzymes. The prominent attribute of disease history of this patient is very few hospital visits as compared to the Cases \#1 and \#2.

PGx testing in three presented cases led to several recommendations for changes in medication regimen in two patients with cytochrome polymorphisms. Most notably, for the Case \#1, primary care provider was suggested to change atorvastatin to rosuvastatin and to consider discontinuing monteleukast and fluticasone/vilanterol, as well as instead of prednisone, prescribe methylprednisolone for asthma treatment, whereas for the Case \#2, increase in dose of carvedilol was recommended. Due to complexity of medication regimen of these patients and common practice in exercising considerable caution when changing drug regimen in older adults, consultations with patients' respective pulmonologists and cardiologists were recommended. Out of three arbitrarily selected individuals, two patients tested positively for major CYP polymorphisms, which potentially could affect efficacy of their drug regimen. All three patients had combinations of chronic heart and lung conditions coupled with other comorbidities. They received guideline-concordant care prescribed by the same providers and were reported to be compliant with their therapy. Despite similar approaches to their care, the two individuals with major CYP polymorphisms had much higher hospitalization rates than the patient who did not have mutant alleles leading to altered functionality of cytochrome enzymes, although this patient was older and had multiple comorbidities also.

The case series design employed in this study belongs to a group of descriptive studies that primarily are used for hypothesis-generating purposes. ${ }^{35}$ Based on the aforementioned case series review, it is feasible to 
hypothesize then that CYP polymorphism may represent an additional risk factor for higher hospitalization rates in older adults with polypharmacy and that PGx testing in frequently hospitalized older adults with polypharmacy may help in optimizing their therapy. Current literature, however, lacks definitive evidence to support this hypothesis, though several recent reports described as follows lend support to this hypothesis.

A recent observational study compared a prospective cohort of older adults whose medication regimen was optimized according to PGx testing results to a propensity scorematched historical cohort. ${ }^{36}$ The results of this study showed that patients treated according to pharmacogenomics-guided treatment plan had a significant decrease in hospitalizations and emergency department visits with average cost savings in the amount of US\$218. In an interesting instructive case presented by Isidoro-García et al, ${ }^{37}$ a 74 -year-old woman with multiple comorbidities and polypharmacy developed erythrodermic psoriasis on admission to a cardiology department with CHF, atrial fibrillation, and chronic renal failure. A personalized PGx analysis found that this patient was homozygous for CYP $3 \mathrm{~A} 5 * 3$ and heterozygous for $3435 \mathrm{C}>\mathrm{T}$ MDR1. Following pharmacogenomics-guided medication regimen readjustment, the patient improved remarkably with complete remission of coetaneous symptoms and control of renal, hepatic, and cardiac symptomatology. Urgent need for effective approaches for medication optimization in older adults with polypharmacy was demonstrated by Nightingale et al. ${ }^{38}$ Using Beers ${ }^{39}$ and STOPP/START ${ }^{40}$ criteria, a retrospective medication use examination was conducted in ambulatory older adults with cancer. The prevalence of polypharmacy, excessive polypharmacy, and potentially inappropriate medication use was $41 \%, 43 \%$, and $51 \%$, respectively. Another study analyzed the impact of applying a PGx approach to the medical management of older adults with polypharmacy in a long-term care facility ${ }^{41}$ Applying pharmacogenomics-guided recommendations across this patient population resulted in medication optimization for $50 \%$ of the polypharmacy population tested with estimated annual savings of US\$621 per patient. As cost-effectiveness of PGx testing is considered one of the major barriers toward its wide introduction to clinical practice, ${ }^{42}$ these results uncover potential approaches to overcome this barrier by targeting subgroups of patients for whom PGx testing may result in substantial cost savings such as older adults with polypharmacy. Further studies with appropriate design and sample size are necessary to identify prevalence of CYP polymorphisms in frequently hospitalized older adults and systematically test the hypothesis that PGx polymorphism is an independent risk factor for frequent hospitalizations in older adults with polypharmacy. Effective optimization of medication regimen in older adults with polypharmacy requires fundamental shift in clinical decision making from "one gene-one drug-one disease" paradigm to "pharmacogenomic profile-polypharmacy-multimorbidity" paradigm.

Overall, multiple barriers still exist for implementing PGx testing in routine clinical care. Some of the most prominent barriers encountered in this small study and potential ways to address them are listed in Table 3. The clinical efficacy of precision medicine approaches in older adults has to be assessed in definitive randomized trials. Most studies of PGx clinical efficacy to date have focused on one drug and one gene ${ }^{43}$ however, we submit that precision medicine should be addressing the more pressing issue of polypharmacy and/or multiple comorbidities. In order to utilize precision medicine approaches in routine clinical care multiple challenges have to be addressed to optimize care of older adults.

Recent surveys demonstrated lack of comprehensive skills in majority of clinicians to take full advantage of the potential of pharmacogenetic testing..$^{44}$ Primary and subspecialty providers are unsure of how to carry out testing,

Table 3 Barriers for implementing PGx testing in older adults with polypharmacy in routine clinical care

\begin{tabular}{|c|c|}
\hline Barrier & How to address \\
\hline $\begin{array}{l}\text { Limited number of } \\
\text { certified PGx facilities }\end{array}$ & $\begin{array}{l}\text { Create a comprehensive public resource } \\
\text { of certified facilities that is maintained and } \\
\text { curated by designated academic centers and } \\
\text { industry }\end{array}$ \\
\hline $\begin{array}{l}\text { Lack of provider } \\
\text { knowledge }\end{array}$ & $\begin{array}{l}\text { Develop online CME courses and training } \\
\text { tools }\end{array}$ \\
\hline $\begin{array}{l}\text { Complexity of PGx } \\
\text { testing results }\end{array}$ & Introduce evidence-based clinical pathways \\
\hline $\begin{array}{l}\text { Uncertainty in } \\
\text { interpretation of PGx } \\
\text { results }\end{array}$ & $\begin{array}{l}\text { Create and maintain evidence-based } \\
\text { consensus guidelines }\end{array}$ \\
\hline $\begin{array}{l}\text { Lack of clinical evidence } \\
\text { on using PGx results }\end{array}$ & $\begin{array}{l}\text { Conduct clinical trials demonstrating clinical } \\
\text { efficacy }\end{array}$ \\
\hline $\begin{array}{l}\text { EMR does not support } \\
\text { PGx result storage and } \\
\text { review }\end{array}$ & $\begin{array}{l}\text { Develop informatics solutions for storage, } \\
\text { representation, and secure exchange of PGx } \\
\text { data }\end{array}$ \\
\hline $\begin{array}{l}\text { Lack of computerized } \\
\text { decision support }\end{array}$ & $\begin{array}{l}\text { Introduce intelligent decision support allowing } \\
\text { to account simultaneously for multiple } \\
\text { drug-gene and drug-drug interactions and } \\
\text { assist in medication regimen optimization }\end{array}$ \\
\hline $\begin{array}{l}\text { Lack of patient } \\
\text { education }\end{array}$ & $\begin{array}{l}\text { Develop interactive apps to support patient } \\
\text { engagement in medication management and } \\
\text { facilitate patient-provider communication on } \\
\text { PGx testing }\end{array}$ \\
\hline
\end{tabular}

Abbreviations: PGx, pharmacogenomic; CME, continuing medical education; EMR, electronic medical record. 
where to process samples, and how to follow-up on testing results. ${ }^{45,46}$ Development, evaluation, and implementation of effective tools assisting providers in the use and interpretation of pharmacogenetic tests should be a high priority for biomedical informatics researchers. Such tools may provide support for multiple aspects pertinent to optimal use of PGx testing. ${ }^{47}$ Since limited information is available on certified facilities for PGx testing and type of services they provide, creation of a comprehensive online public resource of certified facilities which is maintained and curated by a consortium of academic centers and industry representatives may be warranted. To address lack of provider knowledge, introduction of online continuing medical education courses and training tools may facilitate diffusion of pharmacogenomics into routine clinical practice. Due to inherent complexity of this novel methodology, introduction of evidence-based clinical pathways may promote best practices in PGx applications. ${ }^{48}$ Electronic health records have to include functionality that supports storage, exchange, analysis, and presentation of PGx results coupled with intelligent decision support allowing to account simultaneously for multiple drug-drug, drug-gene, and drug-drug-gene interactions and assist in drug regimen optimization. ${ }^{49}$ Finally, development of interactive apps to educate patients about PGx testing and to engage them in medication management based on individual genetic test results will facilitate patient-provider communication and ensure patient acceptance of PGx testing as an opportunity to personalize their medication regimen and improve their quality of life. ${ }^{50}$ Several innovative demonstration projects including Pharmacogenomic Resource for Enhanced Decisions in Care and Treatment at the Vanderbilt University Medical Center" ${ }^{51}$ and "1200 Patients Project" at the University of Chicago $\mathrm{O}^{52}$ are currently underway and are expected to provide insight on addressing the aforementioned barriers in practical implementation of pharmacogenomics.

Our study has several limitations. The case series design employed in the study can be helpful in generating a hypothesis but is insufficient to demonstrate causality. As polypharmacy is considered to be a significant risk factor for ADR, assessment of correlation between pharmacogenomics and treatment complications in the presence of polypharmacy should be a very interesting subject of a systematic research inquiry. However, a systematic review of treatment complications was outside scope of this pilot case series study and will be a subject for further explorations in the future. The current study could not reflect pharmacodynamic aspects of drug-gene interactions, since our pharmacogenetic panel included only genes responsible for drug metabolism. Since drug-gene interactions were the main focus of our exploratory analysis, drug-drug-gene interactions as well as the presence of potentially inappropriate medications based on Beers ${ }^{39}$ or STOPP/START ${ }^{40}$ criteria were not systematically reviewed. Nevertheless, even within the scope of this focused analysis, we were able to demonstrate an important potential of PGx testing in older adults with polypharmacy. More comprehensive analysis undoubtedly can further exemplify the need to review drugs, genes, and other relevant interactions in the elderly in a coordinated way. Future studies should be able to employ technologies accounting for multiple aspects of medication management in older adults including potentially inappropriate medications, pharmacokinetics, pharmacodynamics, phenoconversion, and drug-drug, drug-food, drug-disease, drug-gene, drug-drug-gene interactions, and cumulative drug-drug interactions. ${ }^{53}$

\section{Conclusion}

Although multiple challenges to implementation of precision medicine in routine clinical practice exist, there is enormous potential in using PGx testing in older adults with polypharmacy. Our case series study provides instructive insight on the potential of precision medicine in this rapidly growing population. The review of our cases led us to hypothesize that cytochrome polymorphism may potentially be an important factor in increasing hospitalization rates in older adults with polypharmacy. Our next step is to assess the frequency of CYP450 polymorphisms in older adults with polypharmacy based on hospitalization rates. If higher rates of CYP450 polymorphisms are demonstrated in older adults with polypharmacy who are frequently admitted to hospital, then testing for CYP450 polymorphisms may be indicated in this group of patients on a routine basis to optimize drug therapy and reduce readmissions.

\section{Disclosure}

The authors report no conflicts of interest in this work.

\section{References}

1. Rohrer JE, Garrison G, Oberhelman SA, Meunier MR. Epidemiology of polypharmacy among family medicine patients at hospital discharge. J Prim Care Community Health. 2013;4(2):101-105.

2. Qato DM, Alexander GC, Conti RM, et al. Use of prescription and overthe-counter medications and dietary supplements among older adults in the United States. JAMA. 2008;300(24):2867-2878.

3. Maher RL, Hanlon J, Hajjar ER. Clinical consequences of polypharmacy in elderly. Expert Opin Drug Saf. 2014;13(1):57-65.

4. Sehgal V, Bajwa SJ, Sehgal R, Bajaj A, Khaira U, Kresse V. Polypharmacy and potentially inappropriate medication use as the precipitating factor in readmissions to the hospital. J Family Med Prim Care. 2013; 2(2):194-199. 
5. David SP, Johnson SG, Berger AC, et al. Making personalized health care even more personalized: insights from activities of the IOM genomics roundtable. Ann Fam Med. 2015;13(4):373-380.

6. Vivot A, Boutron I, Ravaud P, Porcher R. Guidance for pharmacogenomic biomarker testing in labels of FDA-approved drugs. Genet Med. 2015;17(9):733-738.

7. Cavallari LH, Jeong H, Bress A. Role of cytochrome P450 genotype in the steps toward personalized drug therapy. Pharmgenomics Pers Med. 2011;4:123-136.

8. Bielinski SJ, Olson JE, Pathak J, et al. Preemptive genotyping for personalized medicine: design of the right drug, right dose, right timeusing genomic data to individualize treatment protocol. Mayo Clin Proc. 2014;89(1):25-33

9. Kaufman AL, Spitz J, Jacobs M, et al. Evidence for clinical implementation of pharmacogenomics in cardiac drugs. Mayo Clin Proc. 2015;90(6):716-729.

10. Johnson M, Richard C, Bogdan R, Kidd R. Warfarin dosing in a patient with CYP2C9(*)3(*)3 and VKORC1-1639 AA genotypes. Case Rep Genet. 2014;2014:413743.

11. Li J, Bluth MH. Pharmacogenomics of drug metabolizing enzymes and transporters: implications for cancer therapy. Pharmgenomics Pers Med. 2011;4:11-33.

12. Deeken JF, Figg WD, Bates SE, Sparreboom A. Toward individualized treatment: prediction of anticancer drug disposition and toxicity with pharmacogenetics. Anticancer Drugs. 2007;18(2):111-126.

13. Wijnen PA, Op den Buijsch RA, Drent M, et al. Review article: the prevalence and clinical relevance of cytochrome $\mathrm{P} 450$ polymorphisms. Aliment Pharmacol Ther. 2007;26(Suppl 2):211-219.

14. Oetjens MT, Denny JC, Ritchie MD, et al. Assessment of a pharmacogenomic marker panel in a polypharmacy population identified from electronic medical records. Pharmacogenomics. 2013;14(7): 735-744.

15. Hiratsuka M, Sasaki T, Mizugaki M. Genetic testing for pharmacogenetics and its clinical application in drug therapy. Clin Chim Acta 2006;363(1-2):177-186.

16. Thorn CF, Klein TE, Altman RB. PharmGKB: the pharmacogenomics knowledge base. Methods Mol Biol. 2013;1015:311-320.

17. Finkelstein J, Cha E, Scharf SM. Chronic obstructive pulmonary disease as an independent risk factor for cardiovascular morbidity. Int J Chron Obstruct Pulmon Dis. 2009;4:337-349.

18. Chaudhry SI, McAvay G, Chen S, et al. Risk factors for hospital admission among older persons with newly diagnosed heart failure: findings from the Cardiovascular Health Study. J Am Coll Cardiol. 2013;61(6):635-642.

19. Sim SC, Ingelman-Sundberg M. Pharmacogenomic biomarkers new tools in current and future drug therapy. Trends Pharmacol Sci. 2011;32(2):72-81.

20. Lee SJ, Goldstein JA. Functionally defective or altered CYP3A4 and CYP3A5 single nucleotide polymorphisms and their detection with genotyping tests. Pharmacogenomics. 2005;6(4):357-371.

21. Lamba JK, Lin YS, Schuetz EG, Thummel KE. Genetic contribution to variable human CYP3A-mediated metabolism. Adv Drug Deliv Rev. 2002;54(10):1271-1294

22. Flockhart DA, O'Kane D, Williams MS, et al. Pharmacogenetic testing of CYP2C9 and VKORC1 alleles for warfarin. American College of Medical Genetics Policy Statement. Genet Med. 2008;10(2):139-150.

23. Meckley LM, Wittkowsky AK, Rieder MJ, Rettie AE, Veenstra DL. An analysis of the relative effects of VKORC1 and CYP2C9 variants on anticoagulation related outcomes in warfarin-treated patients. Thromb Haemost. 2008;100(2):229-239.

24. Zhou SF. Polymorphism of human cytochrome P450 2D6 and its clinical significance: Part I. Clin Pharmacokinet. 2009;48(11):689-723.

25. Lymperopoulos A, McCrink KA, Brill A. Impact of CYP2D6 genetic variation on the response of the cardiovascular patient to carvedilol and metoprolol. Curr Drug Metab. 2015;17(1):30-36.

26. Blake CM, Kharasch ED, Schwab M, Nagele P. A meta-analysis of CYP2D6 metabolizer phenotype and metoprolol pharmacokinetics. Clin Pharmacol Ther. 2013;94(3):394-399.
27. Hocum BT, White JR Jr, Heck JW3, et al. Cytochrome P-450 gene and drug interaction analysis in patients referred for pharmacogenetic testing. Am J Health Syst Pharm. 2016;73(2):61-67.

28. Zhou SF. Polymorphism of human cytochrome P450 2D6 and its clinical significance: part II. Clin Pharmacokinet. 2009;48(12):761-804.

29. Verbeurgt P, Mamiya T, Oesterheld J. How common are drug and gene interactions? Prevalence in a sample of 1143 patients with CYP2C9, CYP2C19 and CYP2D6 genotyping. Pharmacogenomics. 2014;15(5):655-665.

30. Baudhuin LM, Miller WL, Train L, et al. Relation of ADRB1, CYP2D6, and UGT1A1 polymorphisms with dose of, and response to, carvedilol or metoprolol therapy in patients with chronic heart failure. $\mathrm{Am} \mathrm{J}$ Cardiol. 2010;106(3):402-408.

31. Bae JW, Jang CG, Lee SY. Effects of CYP2D6 genetic polymorphism on the pharmacokinetics of carvedilol. FASEB J. 2007;21:1b363.

32. Shihmanter R, Nulman I, Goland S, et al. Variation in the CYP2D6 genotype is not associated with carvedilol dose changes in patients with heart failure. J Clin Pharm Ther. 2014;39(4):432-438.

33. Relling MV, Klein TE. CPIC: Clinical Pharmacogenetics Implementation Consortium of the Pharmacogenomics Research Network. Clin Pharmacol Ther. 2011;89(3):464-467.

34. Swen JJ, Nijenhuis M, de Boer A, et al. Pharmacogenetics: from bench to byte - an update of guidelines. Clin Pharmacol Ther. 2011; 89(5):662-673.

35. Carey TS, Boden SD. A critical guide to case series reports. Spine. 2003;28(15):1631-1634.

36. Brixner D, Biltaji E, Bress A, et al. The effect of pharmacogenetic profiling with a clinical decision support tool on healthcare resource utilization and estimated costs in the elderly exposed to polypharmacy. J Med Econ. 2016;19(3):213-228.

37. Isidoro-García M, Sánchez-Martín A, García-Berrocal B, RománCurto C. Primun non nocere, polypharmacy and pharmacogenetics. Pharmacogenomics. 2015;16(17):1903-1905.

38. Nightingale G, Hajjar E, Swartz K, Andrel-Sendecki J, Chapman A. Evaluation of a pharmacist-led medication assessment used to identify prevalence of and associations with polypharmacy and potentially inappropriate medication use among ambulatory senior adults with cancer. J Clin Oncol. 2015;33(13):1453-1459.

39. American Geriatrics Society 2012 Beers Criteria Update Expert Panel. American Geriatrics Society updated Beers Criteria for potentially inappropriate medication use in older adults. J Am Geriatr Soc. 2012;60(4):616-631.

40. Gallagher P, Ryan C, Byrne S, Kennedy J, O'Mahony D. STOPP (Screening Tool of Older Person's Prescriptions) and START (Screening Tool to Alert doctors to Right Treatment). Consensus validation. Int $J$ Clin Pharmacol Ther. 2008;46(2):72-83.

41. Saldivar JS, Taylor D, Sugarman EA, et al. Initial assessment of the benefits of implementing pharmacogenetics into the medical management of patients in a long-term care facility. Pharmgenomics Pers Med. 2016;9:1-6.

42. Shah RR, Gaedigk A, LLerena A, Eichelbaum M, Stingl J, Smith RL. CYP450 genotype and pharmacogenetic association studies: a critical appraisal. Pharmacogenomics. 2016;17(3):259-275.

43. Lee JS, Cheong HS, Kim LH, et al. Screening of genetic polymorphisms of CYP3A4 and CYP3A5 genes. Korean J Physiol Pharmacol. 2013;17(6):479-484.

44. Johansen Taber KA, Dickinson BD. Pharmacogenomic knowledge gaps and educational resource needs among physicians in selected specialties. Pharmgenomics Pers Med. 2014;7:145-162.

45. Haga SB, Burke W, Ginsburg GS, Mills R, Agans R. Primary care physicians' knowledge of and experience with pharmacogenetic testing. Clin Genet. 2012;82(4):388-394.

46. Obara T, Abe S, Satoh M, Gutiérrez Ubeda SR, Yoshimachi S, Goto T. Awareness regarding clinical application of pharmacogenetics among Japanese pharmacists. Pharmgenomics Pers Med. 2015;8:35-41.

47. Abul-Husn NS, Owusu Obeng A, Sanderson SC, Gottesman O, Scott SA. Implementation and utilization of genetic testing in personalized medicine. Pharmgenomics Pers Med. 2014;7:227-240. 
48. Mikat-Stevens NA, Larson IA, Tarini BA. Primary-care providers' perceived barriers to integration of genetics services: a systematic review of the literature. Genet Med. 2015;17(3):169-176.

49. Overby CL, Erwin AL, Abul-Husn NS, et al. Physician attitudes toward adopting genome-guided prescribing through clinical decision support. J Pers Med. 2014;4(1):35-49.

50. Mills R, Voora D, Peyser B, Haga SB. Delivering pharmacogenetic testing in a primary care setting. Pharmgenomics Pers Med. 2013;6: $105-112$.

51. Carlson B. Vanderbilt pioneers bedside genetics. Biotechnol Healthc. 2012;9(2):31-32.
52. O’Donnell PH, Danahey K, Jacobs M, et al. Adoption of a clinical pharmacogenomics implementation program during outpatient care-initial results of the University of Chicago "1,200 Patients Project". Am J Med Genet C Semin Med Genet. 2014;166C(1):68-75.

53. Thirumaran RK, Heck JW, Hocum BT. CYP450 genotyping and cumulative drug-gene interactions: an update for precision medicine. Pers Med. 2016;13(1):5-8. 


\section{Supplementary materials}

Table SI Summary of potential drug-gene and drug-drug interactions in Case \#I

\begin{tabular}{|c|c|c|c|}
\hline & Impact & Action & Mechanism \\
\hline \multicolumn{4}{|l|}{ Drug-gene interactions } \\
\hline $\begin{array}{l}\text { Atorvastatin calcium and } \\
\text { CYP3A4/CYP3A5 }\end{array}$ & Major & $\begin{array}{l}\text { Consider dose } \\
\text { reduction }\end{array}$ & $\begin{array}{l}\text { CYP3A4/3A5 poor metabolizer status may lead to decreased } \\
\text { metabolism of atorvastatin }\end{array}$ \\
\hline $\begin{array}{l}\text { Fluticasone/salmeterol and } \\
\text { CYP3A4/CYP3A5 }\end{array}$ & Major & Monitor therapy & $\begin{array}{l}\text { CYP3A4/3A5 poor metabolizer status may result in decreased } \\
\text { metabolism of fluticasone/salmeterol }\end{array}$ \\
\hline $\begin{array}{l}\text { Lidocaine/prilocaine and } \\
\text { CYP3A4/CYP3A5 }\end{array}$ & Major & Monitor therapy & $\begin{array}{l}\text { Poor metabolizer status may result in decreased metabolism } \\
\text { of CYP3A4/CYP3A5 substrates (lidocaine) }\end{array}$ \\
\hline $\begin{array}{l}\text { Losartan/hydrochlorothiazide } \\
\text { and CYP3A4/CYP3A5 }\end{array}$ & Moderate & Monitor therapy & $\begin{array}{l}\text { Poor metabolizer status may result in decreased metabolism } \\
\text { of CYP3A4/CYP3A5 substrates (losartan) }\end{array}$ \\
\hline $\begin{array}{l}\text { Montelukast sodium and } \\
\text { CYP3A4/CYP3A5 }\end{array}$ & Major & Monitor therapy & $\begin{array}{l}\text { CYP3A4/3A5 poor metabolizer may cause decreased } \\
\text { metabolism of montelukast }\end{array}$ \\
\hline $\begin{array}{l}\text { Prednisone and CYP3A4/ } \\
\text { CYP3A5 }\end{array}$ & Moderate & Monitor therapy & $\begin{array}{l}\text { Due to CYP3A4/3A5 poor metabolizer status, less prednisone } \\
\text { (inactive) may be converted to prednisolone (active form) }\end{array}$ \\
\hline $\begin{array}{l}\text { Roflumilast and CYP3A4/ } \\
\text { CYP3A5 }\end{array}$ & Moderate & Monitor therapy & $\begin{array}{l}\text { CYP3A4/3A5 poor metabolizer status may result in increased } \\
\text { exposure to roflumilast }\end{array}$ \\
\hline \multicolumn{4}{|c|}{ Drug-drug interactions based on CYP450 metabolism } \\
\hline Primidone and roflumilast & Major & Avoid combination & $\begin{array}{l}\text { CYP3A4 inducers (primidone) may decrease the serum } \\
\text { concentration of roflumilast }\end{array}$ \\
\hline $\begin{array}{l}\text { Atorvastatin calcium and } \\
\text { primidone }\end{array}$ & Major & Consider modification & $\begin{array}{l}\text { CYP3A4 inducers (primidone) may increase the metabolism } \\
\text { of CYP3A4 substrates }\end{array}$ \\
\hline $\begin{array}{l}\text { Losartan/hydrochlorothiazide } \\
\text { and primidone }\end{array}$ & Major & Consider modification & $\begin{array}{l}\text { CYP3A4 inducers (primidone) may increase the metabolism } \\
\text { of CYP3A4 substrates }\end{array}$ \\
\hline $\begin{array}{l}\text { Diclofenac potassium and } \\
\text { primidone }\end{array}$ & Moderate & Monitor therapy & $\begin{array}{l}\text { CYP2C9 inducers (primidone) may decrease the serum } \\
\text { concentration of diclofenac }\end{array}$ \\
\hline Prednisone and primidone & Moderate & Monitor therapy & $\begin{array}{l}\text { CYP3A4 inducers (primidone) may decrease the serum } \\
\text { concentration of prednisone }\end{array}$ \\
\hline \multicolumn{4}{|c|}{ Non-CYP450 drug-drug interactions } \\
\hline $\begin{array}{l}\text { Meclizine } \mathrm{HCl} \text { and tiotropium } \\
\text { bromide }\end{array}$ & Major & Avoid combination & $\begin{array}{l}\text { Anticholinergic agents may enhance the anticholinergic effect } \\
\text { of tiotropium }\end{array}$ \\
\hline $\begin{array}{l}\text { Nortriptyline } \mathrm{HCl} \text { and } \\
\text { tiotropium bromide }\end{array}$ & Major & Avoid combination & $\begin{array}{l}\text { Anticholinergic agents may enhance the anticholinergic effect } \\
\text { of tiotropium }\end{array}$ \\
\hline $\begin{array}{l}\text { Oxybutynin chloride and } \\
\text { tiotropium bromide }\end{array}$ & Major & Avoid combination & $\begin{array}{l}\text { Anticholinergic agents may enhance the anticholinergic effect } \\
\text { of tiotropium }\end{array}$ \\
\hline $\begin{array}{l}\text { Aspirin and diclofenac } \\
\text { potassium }\end{array}$ & Major & Consider modification & $\begin{array}{l}\text { An increased risk of bleeding may be associated with use of } \\
\text { this combination }\end{array}$ \\
\hline $\begin{array}{l}\text { Clonidine } \mathrm{HCl} \text { and } \\
\text { metoprolol succinate }\end{array}$ & Major & Consider modification & $\begin{array}{l}\text { Alpha2-agonists may enhance the atrioventricular-blocking } \\
\text { effect of beta-blockers. Beta-blockers may enhance the } \\
\text { rebound hypertensive effect of alpha2-agonists }\end{array}$ \\
\hline $\begin{array}{l}\text { Clonidine } \mathrm{HCl} \text { and } \\
\text { nortriptyline } \mathrm{HCl}\end{array}$ & Moderate & Consider modification & $\begin{array}{l}\text { Tricyclic antidepressants may diminish the antihypertensive } \\
\text { effect of alpha2-agonists }\end{array}$ \\
\hline $\begin{array}{l}\text { Diclofenac potassium and } \\
\text { furosemide }\end{array}$ & Moderate & Consider modification & $\begin{array}{l}\text { Nonsteroidal anti-inflammatory agents may diminish the } \\
\text { diuretic effect of loop diuretics }\end{array}$ \\
\hline $\begin{array}{l}\text { Metoclopramide } \mathrm{HCl} \text { and } \\
\text { nortriptyline } \mathrm{HCl}\end{array}$ & Major & Consider modification & $\begin{array}{l}\text { Metoclopramide may enhance the adverse/toxic effect of } \\
\text { tricyclic antidepressants }\end{array}$ \\
\hline Prednisone and roflumilast & Major & Consider modification & $\begin{array}{l}\text { Roflumilast may enhance the immunosuppressive effect of } \\
\text { prednisone }\end{array}$ \\
\hline $\begin{array}{l}\text { Meclizine } \mathrm{HCl} \text { and } \\
\text { oxybutynin chloride }\end{array}$ & Moderate & Monitor therapy & $\begin{array}{l}\text { Anticholinergic agents may enhance the adverse/toxic effect } \\
\text { of other anticholinergic agents }\end{array}$ \\
\hline $\begin{array}{l}\text { Nortriptyline } \mathrm{HCl} \text { and } \\
\text { oxybutynin chloride }\end{array}$ & Moderate & Monitor therapy & $\begin{array}{l}\text { Anticholinergic agents may enhance the adverse/toxic effect } \\
\text { of other anticholinergic agents }\end{array}$ \\
\hline
\end{tabular}


Table S2 Drug-drug interactions in Case \#2

\begin{tabular}{|c|c|c|c|}
\hline & Impact & Action & Mechanism \\
\hline \multicolumn{4}{|l|}{ Drug-gene interactions } \\
\hline Carvedilol and CYP2D6 & Major & Monitor therapy & $\begin{array}{l}\text { CYPD6 rapid metabolizer status may increase metabolism } \\
\text { of carvedilol }\end{array}$ \\
\hline Warfarin and CYP2C9/VKORCI & Minor & Monitor therapy & $\begin{array}{l}\text { Lower starting warfarin doses may be required due to } \\
\text { reduced VKORCI functionality }\end{array}$ \\
\hline \multicolumn{4}{|c|}{ Drug-drug interactions based on CYP450 metabolism } \\
\hline Carvedilol and losartan potassium & Moderate & Monitor therapy & $\begin{array}{l}\text { CYP2C9 inhibitors (losartan) may increase the serum } \\
\text { concentration of carvedilol }\end{array}$ \\
\hline $\begin{array}{l}\text { Diltiazem } \mathrm{HCl} \text { and fluticasone and } \\
\text { vilanterol }\end{array}$ & Moderate & Monitor therapy & $\begin{array}{l}\text { CYP3A4 inhibitors (diltiazem) may decrease the metabolism } \\
\text { of CYP3A4 substrates }\end{array}$ \\
\hline $\begin{array}{l}\text { Losartan potassium and warfarin } \\
\text { sodium }\end{array}$ & Moderate & Monitor therapy & $\begin{array}{l}\text { CYP2C9 inhibitors (losartan) may decrease the metabolism } \\
\text { of CYP2C9 substrates }\end{array}$ \\
\hline \multicolumn{4}{|c|}{ Non-CYP450 drug-drug interactions } \\
\hline Albuterol sulfate and carvedilol & Major & Avoid combination & $\begin{array}{l}\text { Beta-blockers may diminish the bronchodilatory effect of } \\
\text { beta2-agonists }\end{array}$ \\
\hline $\begin{array}{l}\text { Carvedilol and fluticasone and } \\
\text { vilanterol }\end{array}$ & Major & Avoid combination & $\begin{array}{l}\text { Beta-blockers may diminish the bronchodilatory effect of } \\
\text { beta2-agonists }\end{array}$ \\
\hline Allopurinol and warfarin sodium & Moderate & Consider modification & $\begin{array}{l}\text { Allopurinol may enhance the anticoagulant effect of vitamin } \mathrm{K} \\
\text { antagonists }\end{array}$ \\
\hline $\begin{array}{l}\text { Atorvastatin calcium and diltiazem } \\
\mathrm{HCl}\end{array}$ & Major & Consider modification & $\begin{array}{l}\text { Diltiazem } \mathrm{HCl} \text { may increase the serum concentration of } \\
\text { atorvastatin calcium. Atorvastatin calcium may increase the } \\
\text { serum concentration of diltiazem } \mathrm{HCl}\end{array}$ \\
\hline Carvedilol and tamsulosin $\mathrm{HCl}$ & Moderate & Consider modification & $\begin{array}{l}\text { Beta-blockers may enhance the orthostatic hypotensive } \\
\text { effect of alphal-blockers }\end{array}$ \\
\hline Furosemide and naproxen & Moderate & Consider modification & $\begin{array}{l}\text { Nonsteroidal anti-inflammatory agents may diminish the } \\
\text { diuretic effect of loop diuretics }\end{array}$ \\
\hline Naproxen and warfarin sodium & Moderate & Consider modification & $\begin{array}{l}\text { Nonsteroidal anti-inflammatory drug (nonselective) may } \\
\text { enhance the anticoagulant effect of vitamin } \mathrm{K} \text { antagonists }\end{array}$ \\
\hline
\end{tabular}

Table S3 Drug-drug interactions in Case \#3

\begin{tabular}{|c|c|c|c|}
\hline & Impact & Action & Mechanism \\
\hline \multicolumn{4}{|l|}{ Drug-gene interactions } \\
\hline None & $\mathrm{N} / \mathrm{A}$ & $\mathrm{N} / \mathrm{A}$ & $\mathrm{N} / \mathrm{A}$ \\
\hline \multicolumn{4}{|c|}{ Drug-drug interactions based on CYP450 metabolism } \\
\hline $\begin{array}{l}\text { Amiodarone } \mathrm{HCl} \text { and losartan } \\
\text { potassium }\end{array}$ & Moderate & Monitor therapy & $\begin{array}{l}\text { CYP2C8 inhibitors (moderate) may decrease the metabolism } \\
\text { of CYP2C8 substrates (amiodarone) }\end{array}$ \\
\hline $\begin{array}{l}\text { Diltiazem } \mathrm{HCl} \text { and fluticasone/ } \\
\text { vilanterol }\end{array}$ & Moderate & Monitor therapy & $\begin{array}{l}\text { CYP3A4 inhibitors (diltiazem) may decrease the metabolism } \\
\text { of CYP3A4 substrates (fluticazone) }\end{array}$ \\
\hline Diltiazem $\mathrm{HCl}$ and lidocaine & Moderate & Monitor therapy & $\begin{array}{l}\text { CYP3A4 inhibitors (diltiazem) may decrease the metabolism } \\
\text { of CYP3A4 substrates }\end{array}$ \\
\hline \multicolumn{4}{|c|}{ Non-CYP450 drug-drug interactions } \\
\hline $\begin{array}{l}\text { Albuterol sulfate and } \\
\text { amiodarone } \mathrm{HCl}\end{array}$ & Major & Consider modification & $\begin{array}{l}\text { QTc-prolonging agents may enhance the QTc-prolonging } \\
\text { effect of highest risk QTc-prolonging agents }\end{array}$ \\
\hline $\begin{array}{l}\text { Amiodarone } \mathrm{HCl} \text { and } \\
\text { dabigatran etexilate mesylate }\end{array}$ & Major & Consider modification & $\begin{array}{l}\text { Amiodarone may increase the serum concentration of } \\
\text { dabigatran etexilate }\end{array}$ \\
\hline Amiodarone $\mathrm{HCl}$ and digoxin & Major & Consider modification & $\begin{array}{l}\text { Amiodarone may increase the serum concentration of } \\
\text { cardiac glycosides }\end{array}$ \\
\hline $\begin{array}{l}\text { Amiodarone } \mathrm{HCl} \text { and diltiazem } \\
\mathrm{HCl}\end{array}$ & Major & Consider modification & $\begin{array}{l}\text { Calcium channel blockers may enhance the bradycardic effect } \\
\text { of amiodarone. Sinus arrest has been reported }\end{array}$ \\
\hline $\begin{array}{l}\text { Amiodarone } \mathrm{HCl} \text { and } \\
\text { fluticasone/vilanterol }\end{array}$ & Major & Consider modification & $\begin{array}{l}\text { QTc-prolonging agents may enhance the QTc-prolonging } \\
\text { effect of highest risk QTc-prolonging agents }\end{array}$ \\
\hline
\end{tabular}

Abbreviations: N/A, not available; QTc, corrected QT. 


\section{Publish your work in this journal}

Pharmacogenomics and Personalized Medicine is an international, peerreviewed, open access journal characterizing the influence of genotype on pharmacology leading to the development of personalized treatmen programs and individualized drug selection for improved safety, efficacy and sustainability. This journal is indexed on the American Chemical

Submit your manuscript here: http://www.dovepress.com/pharmacogenomics-and-personalized-medicine-journal
Society's Chemical Abstracts Service (CAS). The manuscript management system is completely online and includes a very quick and fair peer-review system, which is all easy to use. Visit http://www.dovepress. com/testimonials.php to read real quotes from published authors. 